\title{
Stereospecific Coupling of Aromatics with Secondary and Tertiary Boronates
}

\section{Category}

Metal-Mediated

Synthesis

Key words

boron

aryllithium

cross-coupling

SYNFACToth

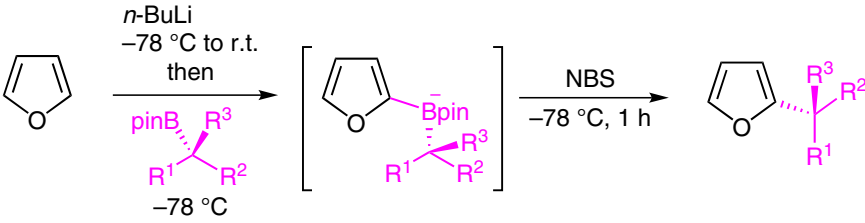

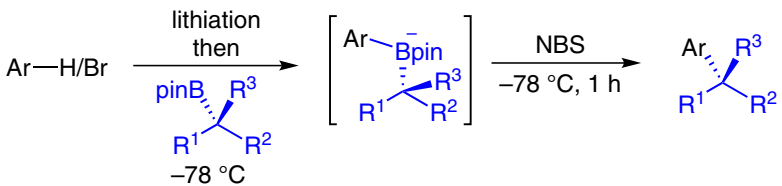

Selected examples:<smiles>CC(c1ccccc1)c1ccco1</smiles>

$93 \%$ yield $\mathrm{er}=93: 7$<smiles>CC(C)(C)OCCCC(CCc1ccccc1)c1ccoc1</smiles>

$85 \%$ yield er $=96: 4$

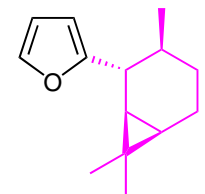

$68 \%$ yield<smiles>CC(CCc1ccccc1)c1cc2ccccc2n1C</smiles>

$86 \%$ yield er $=98: 2$<smiles>O=C(c1ccco1)N1CCCC1c1ccco1</smiles>

$74 \%$ yield er $=93: 7$<smiles>COc1cc(OC)cc(C(C)CCc2ccccc2)c1</smiles>

$83 \%$ yield er $=98: 2$<smiles>CC(C)CC(C)(c1ccccc1)c1ccco1</smiles>

$76 \%$ yield er > 99:1

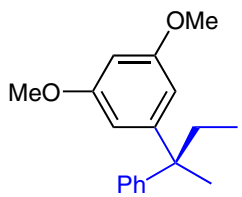

$63 \%$ yield er > 99:1
Significance: Aggarwal and co-workers report an effective, general method for coupling electronrich (hetero)aromatics with enantioenriched secondary and tertiary boronic esters. The reaction involves the initial formation of a boronate complex followed by activation of the electron-rich aromatic by NBS, which triggers a stereospecific 1,2-migration and subsequent eliminationrearomatization.
Comment: The methodology uses simple, readily available reagents and proceeds without transition metals. Broad scope with respect to the boronic ester and the electron-rich aromatic was illustrated, and the reactions proceeded with complete stereospecificity. 